\title{
Context sensitivity and the semantics of count nouns in the evaluation of partial objects by children and adults
}

\author{
Kristen SYRETT ${ }^{1}$ (D) and Athulya ARAVIND ${ }^{2}$ \\ ${ }^{1}$ Rutgers, The State University of New Jersey-New Brunswick, USA and ${ }^{2}$ Massachusetts Institute of \\ Technology, USA \\ Corresponding author: Kristen Syrett, Rutgers The State University of New Jersey - Linguistics 18 Seminary \\ Place New Brunswick New Jersey 08901-8554 United States. E-mail: kristen.syrett@rutgers.edu
}

(Received 22 July 2019; revised 24 August 2020; accepted 2 January 2021;

first published online 12 March 2021)

\begin{abstract}
Previous research has documented that children count spatiotemporally-distinct partial objects as if they were whole objects. This behavior extends beyond counting to inclusion of partial objects in assessment and comparisons of quantities. Multiple accounts of this performance have been proposed: children and adults differ qualitatively in their conceptual representations, children lack the processing skills to immediately individuate entities in a given domain, or children cannot readily access relevant linguistic alternatives for the target count noun. We advance a new account, appealing to theoretical proposals about underspecification in nominal semantics and the role of the discourse context. Our results demonstrate that there are limits to which children allow partial objects to serve as wholes, and that under certain conditions, adult performance resembles that of children by allowing in partial objects. We propose that children's behavior is in fact licensed by the inherent context dependence of count nouns.
\end{abstract}

Keywords: Objects; count nouns; nominals; sortals; context; semantics

\section{Introduction}

Among the first words entering into a child's receptive and productive vocabulary are count nouns such as cup and ball. It might stand to reason, then, that children are aware of what kind of object referents these words pick out in the world. Indeed, in many instances, they do. Even as early as six months of age, infants are able to lock onto a visual image of a corresponding count noun when given a choice between an exemplar of that category and a competitor (Bergelson \& Swingley, 2015). At 12 months of age, infants appear to recognize that each distinct count noun uttered by a speaker signals the presence of a distinct object kind (Xu, 2002, 2007; Xu, Cote \& Baker, 2005; Dewar \& Xu, 2007, 2009). And at 15 months of age, novel words presented in a count noun frame focus infants' attention on object categories (rather

(C) The Author(s), 2021. Published by Cambridge University Press. This is an Open Access article, distributed under the terms of the Creative Commons Attribution licence (http://creativecommons.org/licenses/by/4.0/), which permits unrestricted re-use, distribution and reproduction, provided the original article is properly cited. 


\section{detached parts separated detached parts aligned}

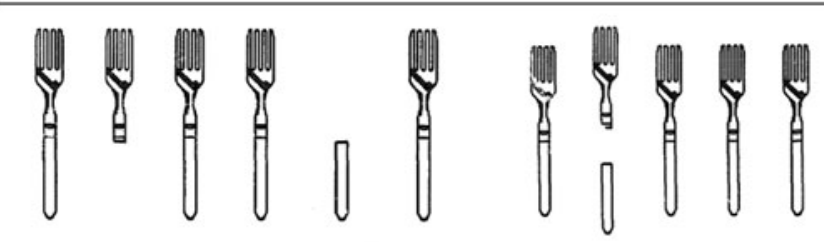

Figure 1. Figures 1 and 2 from Shipley and Shepperson (1990) presenting 'homogeneous familiar arrays' from their Experiments 1 and 2, in which participants were asked either Can you count the things? or Can you count the forks?

than properties or events) and support generalization to new instances (Waxman \& Markow, 1995; Balaban \& Waxman, 1997; Waxman \& Braun, 2005). As children enter into the preschool years, they also demonstrate knowledge that there is a distinction between count and mass nouns in their ability to pick out a discrete object or a substance (Gordon, 1985; Soja, 1992; Bloom, 1994). At the same time, they are not so tightly connected to the idea that a count noun picks out a whole object that they cannot be flexible in the interpretation of count nouns. Children of the same age will also allow a novel count noun to have a 'collective' interpretation, as a label for a plurality of individuals (just as a 'forest' is a collection of trees, or one can have a 'stack' of books) (Bloom \& Kelemen, 1995).

In spite of this nascent awareness of the nominal domain, young children's treatment of count nouns does not always coincide with that of adults. In a now-classic set of studies reported in Shipley and Shepperson (1990), children were shown sets of whole and discrete partial objects (DPOs) and asked to count what was there. The displays were similar to those shown in Figure 1. The instructions took the form of either a "General request" (e.g., Can you count the things?) or a "Specific request" (e.g., Can you count the forks?). Shipley and Shepperson were interested in what children did with the DPOs. They measured their behavior by evaluating their counting strategies.

Participants' counting strategies were labeled as "Count-All" (in which each whole and each DPO were included in the count), "Count-Combined" (in which whole objects were counted, and the parts were 'fused' and treated as a whole object), and "Count-Wholes" (in which only the whole objects were counted. Shipley and Shepperson (1990) predicted that 'count-all' responses would be more likely with general requests to count THINGS relative to specific requests featuring the count nouns. While this counting behavior was manifested by adults, children's strategies did not vary with the form of the request. They consistently included the DPOs. While the arrangement of objects, as shown above, had an influence ( $89 \%$ v. $56 \%$ Count-All responses, respectively), and some children did display a "CountCombined" (or 'fusing') response, the vast majority of children were inclined to "treat each DPO as a countable entity" (pg. 116), even when they recognized it as a broken whole object. This counting behavior may seem quite surprising, as Gelman and Gallistel (the authors of the seminal book The Child's Understanding of Number, 1976) have observed, "Children of preschool age sometimes give surprising answers to apparently simple questions" (pg. 1). 
This set of findings prompted a series of intriguing follow-up studies in subsequent years, which we review in Section 2, aiming to pin down the source of children's response pattern and explain what children's performance indicates about their interpretation of basic count nouns like fork, the mapping between a count noun and a sortal concept, and what can serve as a referent for a count noun in the world (Wagner and Carey, 2003; Xu, 2007; Melgoza, Pogue \& Barner, 2008; Brooks, Pogue \& Barner, 2011, a.o). Two basic positions have emerged, which we refer to as the CONCEPTUAL ACCOUNT and the PRAGMATIC ACCOUNT. Let us take each in turn.

Faced with their findings, Shipley and Shepperson (1990) argued that children's willingness to include DPOs in their count is a direct reflection of their general disposition to count spatiotemporally discrete objects, perhaps as an imitation of the counting routine modeled for them by their caregiver in accordance with Gelman and Gallistel's (1976) counting principles, in which every distinct object receives its own verbal tag in one-to-one correspondence. Under this account, children must learn that partial objects do not fall under the extension of the count noun label, and thus, what changes are the nominal CONCEPTS themselves.

There are two main challenges to this account. First, this behavior is not limited to counting per se. Second, forced-choice priming of alternative labels (e.g., piece of sock) influences children's counting strategies by decreasing the proportion of DPO counts as wholes (Srinivasan, Chestnut, Li \& Barner, 2013). One would not expect any influence of competing alternative expressions if children's conceptual representations needed to undergo a qualitative shift.

A recent alternative account posits that children's proclivity to treat partial objects as wholes is not a developmental anomaly rooted in the counting routine and conceptual development, but rather is linked to their LINGUISTIC development, and is a direct consequence of the meaning of these count nouns and the competing alternatives. Srinivasan et al. (2013) have argued that the semantics of count nouns like fork are underspecified, providing only partial criteria for identifying units of individuation and quantification. Where adults diverge from children is in knowing how to PRAGMATICALLY ENRICH the meaning of count nouns in a context and restrict their application to whole objects if the candidate referent is a DPO by appealing to more informative alternative expressions that could have been used in that context to describe a referent (e.g., describing it as a piece of fork). Young children, who are known to lack the pragmatic sophistication of adults, are unable to readily access these alternatives for DPOs, just as they may diverge from adults in not immediately accessing the relevant alternatives to calculate a scalar implicature (see Guasti, Chierchia, Crain, Foppolo, Gualmini \& Meroni, 2005; Foppolo, Guasti \& Chierchia, 2012, Skordos \& Papafragou, 2016; Syrett, Austin \& Sánchez, 2021; a.o.). Evidence for the pragmatic 'alternative-based' account comes from the fact that children recognize, when given the option, that piece of fork is a PREFERRED way to describe a partial object, and that they exclude DPOs from their count that already have a familiar label (Srinivasan et al., 2013). This account also faces a challenge, in that even children who recognize (and maybe even report) that the objects are broken, ripped, or pieces might still be inclined to include DPOs in their count.

Both accounts, however, fail to account for one important observation: there are, in fact, instances in which even ADULTS allow DPOs to serve as referents for count nouns. We both present evidence for this observation in Section 3, and present additional experimental evidence of this pattern in this paper. Indeed, theoretical accounts of the semantics of count nouns, which we review, predict this very behavior by 
proposing that nominals are vague, and depend on the context for individuation (see Kamp \& Partee, 1995; Rothstein, 2010; Chierchia, 2010; Landman, 2011; Sutton \& Filip, 2016). Thus, DPOs are predicted to fall under the extension of the count noun in some circumstances, not just for children, and regardless of more precise candidate expressions that could be used to refer to the same object.

In this paper, we actively pursue, and present, novel experimental findings in favor of, an alternative account to the two reviewed above, which we term the SEMANTIC ACCOUNT. Under our account, children are not performing in a way that is qualitatively different from adults by including DPOs in their count. Rather, they behave in a way that is licensed by the semantic representation of nominals, because nominal semantics actually DO allow for partial objects to fall under the extension of the count noun denotation under certain circumstances and in certain contexts. The difference in behavioral performance observed between children and adults is thus not reflective of a difference in underlying conceptual or linguistic knowledge, or linked to a counting or quantification bias. Rather, it is indicative of a difference in how the two groups resolve an inherently vague nominal meaning within a discourse context. As we demonstrate in this paper, children differ from adults in their ability to recognize the features of the context that restrict the domain of application of a count noun, including the speaker's goals and intentions, and probabilistic knowledge about objects and their function in the real world.

This claim is further bolstered by empirical data demonstrating that adults themselves allow these count nouns to refer to DPOs and for DPOs to figure in to the truth conditions of assertions featuring these count nouns. Thus, the difference in response patterns cannot be attributed solely to participants' ability to access to pragmatically-relevant alternatives, as adults surely have access to these. To be clear, then, like the previous PRAGMATIC alternative-based account, our account depends on the underspecified semantics of count nouns such as fork. But unlike the previous account, our account does not depend on the presence and accessibility of alternatives in a developing lexicon.

In this paper, we present the results of an experiment with both child and adult participants demonstrating four main findings. First, children of the same age featured in previous studies recognize that DPOs are not optimal referents for a count noun compared to a whole object. Second, adults participating in the same study do not take DPOs to be outright illegitimate referents for a count noun. Third, at a certain point in development, children demonstrate a sensitivity to aspects of the context, which influences their assessment of partial objects as count noun referents. Finally, adults are, like children, willing to include DPOs in their count of objects given a count noun prompt, and are also willing to allow DPOs to satisfy the truth conditions of a statement with such count nouns.

The paper is structured as follows. In the next section, we review the main experimental findings from the developmental literature on children's treatment of DPOs, paying particular attention to the corresponding proposals concerning the role of language in scaffolding children towards an adultlike understanding of count nouns. In Section 3, we outline the theoretical proposals concerning the semantics of count nouns that would license such behavior (even in adults), and then turn to experimental findings from adults demonstrating that they, too, allow partial objects to fall under the extension of count nouns. In Sections 4-6, we then present three experiments. The first, including child and adult participants, was designed to move beyond counting and quantification to object reference in a context in which a 
speaker's goals are made explicit. The second and third, with adults, were intended to showcase the willingness of adults to treat DPOs as acceptable instantiations of the count noun, thereby demonstrating a similarity in the treatment of count nouns and DPOs across child and adult populations. Finally, we conclude in Section 7 by reflecting on what our experimental results say about what accounts for the difference between children and adults and what shape the path to adultlike treatment of partial objects must take, connecting these results to others reported independently in the developmental literature, and outlining the questions our findings raise for future research on this topic.

\section{Developmental background}

By the time four- and five-year-olds demonstrate a robust tendency to include DPOs in their count in experimental tasks designed to assess this pattern of performance, they have been producing count nouns such as the ones used in these studies for quite some time. By 30 months of age, the proportion of children producing words such as ball, car, shoe, cup, spoon, bowl, fork, plate, and sock is upwards of .75 (Fenson, Dale, Reznick, Bates, Thal, Pethick, Tomasello, Mervis \& Stiles, 1994; Wordbank.com). Thus, the original findings reported by Shipley and Shepperson (1990) raise the question of what kind of conceptual and linguistic representation these words evoke in young children, if they allow for a partial fork to be counted as a 'fork'. The studies that followed Shipley and Shepperson provided further insight into this question, highlighting in particular the possible role of language in guiding children to become more like adults.

Wagner and Carey (2003) extended the findings of children's proclivity to count spatiotemporally-individuable DPOs as wholes to events. They demonstrated that, when asked "How many X are there?", children count sub-events of a telic event (an 'accomplishment') in a similar manner. Based on these results, they argued that attention to event completion or object wholes takes additional processing skills that are beyond children's capabilities. While adults can individuate automatically, children must rely on linguistic descriptions to parse objects and events, and become increasingly attuned to how language differentiates between parts and wholes, and between incomplete and complete events.

Brooks et al. (2011) demonstrated that children's willingness to allow DPOs to serve the same role as whole objects is not exclusive to the counting scheme, and can be observed in other tasks tapping in to quantification and comparison. In one task, children were shown a whole object (e.g., a ball) divided into two and asked, "How many balls are there?" Children were likely to count the discrete physical objects when giving their count. In another, children were shown a choice between a character who had two whole shoes and a character who had three partial objects (a shoe cut into thirds) and asked "Who has more shoes?" Nearly $80 \%$ of the time, children produced responses that were based on counting partial objects. At the same time, Brooks et al. also demonstrated there are limits to this pattern, and children do not include DPOs indiscriminately.

In an elicitation task, when children were shown a fork broken in two and asked what the character has, they only referred to the objects as whole objects with plural morphology (e.g., two forks) one third of the time. What's more, when asked to count displays of objects that included partial objects with nameable parts or distractor objects of known kinds, children excluded from their count the nameable 
parts and the distractors with known labels. Brooks et al. claimed that children begin with default units of reference that permit divisity of reference (i.e., a string or stone divided in two yields two new referents), and must learn, as they build their lexicon, that parts of things do not always receive the same label as their hosts. Rather, they may get their own name or be signaled as parts by measurement expressions.

Srinivasan et al. (2013) in turn argued that the conceptual representation and semantic component of nominals is underspecified and imprecise with regards to how units of quantification are determined. Language users must then rely upon conversational inference of what a speaker's intended meaning might be, arising from contrast among lexical alternatives, in order to pragmatically enrich these meanings. Under this account, the main difference between children and adults is not housed in the concepts or sortals themselves or children's processing capacity; rather for both age groups, nominals specify partial criteria of individuation, and adults are able to appeal to a broad range of linguistic expressions that serve as alternatives to deduce the unit of quantification.

Promising evidence for this position comes in the form of children's growing recognition that measurement expressions (e.g., pieces of $X$ ) are better at picking out partial objects than basic nominals are. In one task, participants were shown four pieces of sock. Captain Blue either described them as "four socks" or "four pieces of sock" (a measurement expression). Both adults and children said he did a good job with the measure phrase trials, but not with the non-measure phrase trials. In another task, participants were shown a whole object split into two and presented with two descriptions uttered by two different characters. Farmer Brown said it was "two shoes," whereas Captain Blue said it was "two pieces of shoes." Participants were then asked who said it better. Four-year-olds, but not three-year-olds, patterned significantly above chance. However, children who were primed to point to a "piece of sock" before the task were less likely to count partial objects as wholes in a subsequent task. Thus, the more knowledge children have about alternatives - and the more this knowledge is activated - the more adult-like they are.

The picture that has emerged since Shipley and Shepperson (1990)'s seminal work is the following. Across tasks, children allow DPOs to fill the role of whole objects, although they do not do this indiscriminately; and, the more salient and accessible alternative linguistic expressions are to serve as reference to DPOs, the more children are likely to pattern along with adults. Thus, there is a key role of language in context in enriching and precisifying an a priori underspecified semantic representation.

While we find this consolidated position especially appealing, and do not wish to abandon it entirely, especially because it parsimoniously links lexical development with the incremental development of pragmatic skills in a conversational context, we wish to point out one major challenge that this particular alternative-based implementation of a pragmatic proposal faces. Placing the burden primarily on children, due to their inability to access and compare linguistic alternatives, predicts that adults, equipped with all of their conceptual and linguistic knowledge, should still consistently settle in on the whole object as a referent and quantificational unit, and that children who are still not in possession of knowledge of alternatives, should otherwise treat DPOs as non-degraded object referents, in particular, prior to age four. And further, once children are able to access these alternatives, they should no longer allow DPOs to be referents for count nouns, regardless of other contextual differences. As we will show, this is not the case with either age group. So while the pragmatic account is viable as a part of the treatment of DPOs in development, it cannot be the whole story. 
Here, we show that varying other contextual, speaker-oriented goals, apart from measurement expressions, influences children's response patterns, AND that adults, who are in possession of such knowledge, are inclined to allow DPOs into an object count and feed them into the calculation of truth conditions. Thus, while we share a common foundation with the proponents of the previous pragmatic proposal that count nouns are semantically underspecified, and that pragmatics interacts with semantics to enrich meaning, we take a more general view of the role of pragmatics, allowing that under this new approach, while comparison of alternatives MAY play a role, it is but ONE way in which pragmatics can enhance an impoverished semantics. Our proposal is that the context in which a count noun is uttered - both linguistic and extralinguistic - builds upon an underspecified semantic representation to either exclude or include DPOs.

\section{Theoretical background and predictions}

To see why the semantics of nominals might permit reference to partial objects, and inclusion of partial objects as units of quantification, let us turn to a brief review of the semantics of count nouns. Over the years, a number of researchers in the field of semantics have converged upon the idea that where count nouns differ from mass nouns is that they operate on a counting domain that is composed of atomic individuals (Link, 1983; Krifka, 1989; Chierchia, 2010; Rothstein, 2010; Landman, 2011). Thus, one can easily identify 'one' cup, ball, fork, or twig, while one cannot identify 'one' mud or water (although these substances can be quantized with count nouns that measure them out, such as 'drop'). Crucially, what counts as 'one' for count nouns varies from context to context, and count nouns DEPEND on the context to precisify the boundaries on the objects to which the noun applies. This seems relatively clear for evaluating count nouns and their corresponding objects such as bouquet, twig, rope, or fence, but it also applies to nouns such as child or mountain. It furthermore applies to object mass nouns such as kitchenware, where one could, for example, count lids and pots together as one, or count them separately (Sutton \& Filip, 2016). Thus, how one parses the domain of atomic individuals and how one counts depends on relevant features of the context.

This so-called vagueness of boundaries in the nominal domain has been discussed most often with respect to the paradox of the heap, or the Sorites Paradox. The basic idea is this: start with a pile of sand. Take one grain away. Continue to do so. Removing one grain of sand does not immediately change the status of the pile, but at what point do you no longer have a pile of sand? The boundaries between non-pile and pile are not precise, just as the boundaries between what is not tall and what is tall are also fuzzy, and cannot be delineated abstractly (Kennedy, 2007). It is easy then to transition from a discussion about the context dependence and vagueness of count nouns to a discussion on the status of partial objects in light of these proposals. If count nouns denote atomic individuals, and if how those individuals are counted depends on the context and the boundaries are vague, then this opens the door for partial objects (the DPOs in the developmental literature) to have a crack at serving as object referents.

Indeed, Aravind and Syrett (2017) have demonstrated that adults, much like children, allow partial objects to serve as referents for singular definite nominal expressions, which trigger presuppositions of existence and uniqueness. In a presupposition assessment task following (Syrett, Kennedy \& Lidz, 2010), adults were presented with pairs of objects as in Figure 2. They were asked to find the target object (e.g., Find the tennis ball), or reject the request if it could not be fulfilled, 


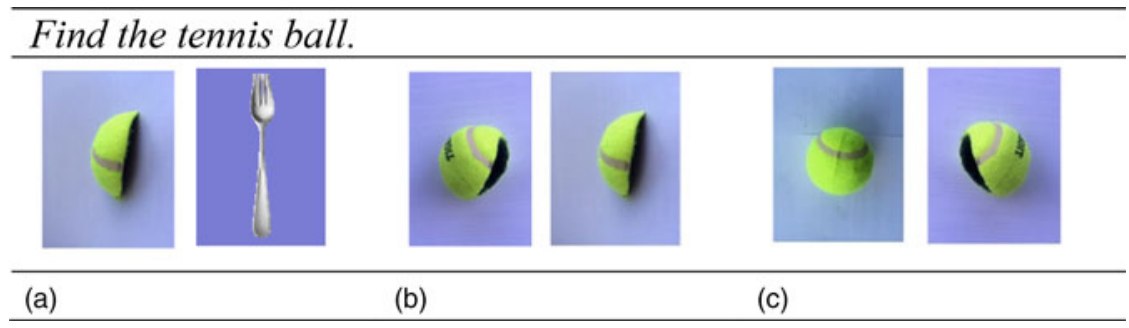

Figure 2. Example of the linguistic prompt paired with three different contexts presented to participants by Aravind and Syrett (2017). Participants were asked to choose one or the other object, or else reject the request.

which could happen if it was infelicitous, because the presuppositions of existence and/or uniqueness associated with the singular definite description were violated (see Russell, 1905; Strawson, 1974). Crucially, most participants did not reject the request in the absence of a whole object $(\mathrm{a}, \mathrm{b})$; nor did they readily accept the request in favor of the whole object when a whole and partial object were present (c). Instead, they patterned as though the DPO served the same role as a whole object, just as children have done in many tasks before, accepting the request only when one of the two objects had the property in question. Thus, the pattern of responses observed in the majority of participants with the pairs shown in Figure 2 was <a. accept, b. reject, c. reject>, demonstrating that a partial object was seen as a potential referent for the count noun, rather than <a. reject, b. reject, c. accept>, as one might have predicted if only a whole object could serve as the referent for the nominal expression. ${ }^{1}$

The combination of the theoretical claims about nominal semantics and adult experimental performance raises the following question: is children's pattern of performance in the previous developmental tasks addressing the status of DPOs a natural outcome of the semantics of count nouns and their context dependence, rather than a reflection of children's immature conceptual capacity? Here, we wish to entertain the answer that it is, and that pragmatics has a key role to play in building upon the semantics. However, we diverge from the pragmatics account previously advanced by claiming it is not solely in terms of the salience and accessibility of more optimal alternative expressions that could have been used, but requires an appeal to context.

Our predictions under the semantic account we are advancing, are as follows. First, certain contexts should elicit more stringent application of the count noun, and there should be LIMITS on the extent to which children allow a DPO to serve as a referent for a count noun. The relevant aspects of the context we highlight here are the role of the object in the context and the speaker's goals. If, however, children differ qualitatively from adults in their conceptual representations, or require lexical alternatives to be primed, manipulation of context should not matter, and children should continue to routinely allow DPOs to fall under the extension of the count noun without hesitation,

\footnotetext{
${ }^{1}$ One potential objection to such an experimental design, however, is that the definite description triggered a presupposition of existence, thereby luring adult participants into accommodating the presupposition and allowing DPOs to be referents for the definite description. While we think the pattern of results obtained within and across trials in that experiment, and the RTs that accompanied these behavioral responses, allow us to argue convincingly against this account, in this study, we move away from definiteness to sidestep such an objection and demonstrate with confidence that adults do indeed allow DPOs to be referents for their corresponding count nouns.
} 
never differentiating between partial and whole exemplars. In Experiment 1, we show that, even at the same age as the previous studies, and even without the introduction of viable salient lexical alternatives, children can be influenced by relevant aspects of the context and assess DPOs as DEGRADED REFERENTS for the relevant count noun in environments where adults also prefer whole objects.

Second, we predict that the pattern of allowing DPOs to serve as referents for a count noun should not be restricted to children, but should also extend to adults, since the default semantics of such count nouns is underspecified, allowing for DPOs to fall under the extension of the count noun in some contexts. In Experiment 2, we demonstrate that adults allow partial objects to be included for the purpose of evaluating the truth conditions of a sentence with the corresponding count noun as true. In Experiment 3, we further demonstrate that adults also allow DPOs with a naturalistic split to be included in a count of objects referenced by the corresponding count noun. Taken together, the results from the children and adults illustrate a semantic and conceptual continuity in development and bear on the role of the context in precisifying the interpretation of count nouns.

\section{Experiment 1}

Because the core question of interest to us is whether children will appeal to information tied to the context to evaluate the kind of object a count noun could apply to, we use a referential task with child and adult participants, rather than continuing the counting/quantificational tasks used in previous developmental studies. In doing so, we also borrowed a page from reliable developmental methodologies to more indirectly tap into their judgments of count noun usage in context, rather than asking children to directly assess truth values of statements.

\section{Participants}

Participants were randomly assigned to one of two between-subject groups, with the number of participants and their gender balanced across these two conditions: 'no goal' and 'goal' ( \pm goal). 34 adult controls participated. 44 children participated (23 boys, 21 girls). The children's overall age was 3;3 to 6;2 ( $\mathrm{M} \mathrm{4;7).} \mathrm{Data} \mathrm{from} \mathrm{two}$ additional children were excluded due to inability to attend to the task.

\section{Stimuli and procedure}

Participants were shown a set of female characters, and told that these girls were all going to make some requests. Participants were then shown a set of animals, and told that the animals were going to try to fulfill the requests. Each trial had the same structure, as shown in Figure 3.

In each case, the girl asked the animal to retrieve an object. The animal was always happy to comply. The animal then left the screen, went into a location (and the participants were asked to recall what the animal was supposed to retrieve, and reminded if they had forgotten), and then the animal returned with an object of some sort. Participants were asked to decide whether or not the animal complied with the request, and to assign them a reward accordingly. They were told that if the animal did not do what they were asked, the animal should receive a black cross, if they 'kind of did it', a blue ribbon, and if they did what they were supposed to do, they got a gold trophy. Thus, the participants were engaged in a ternary judgment 


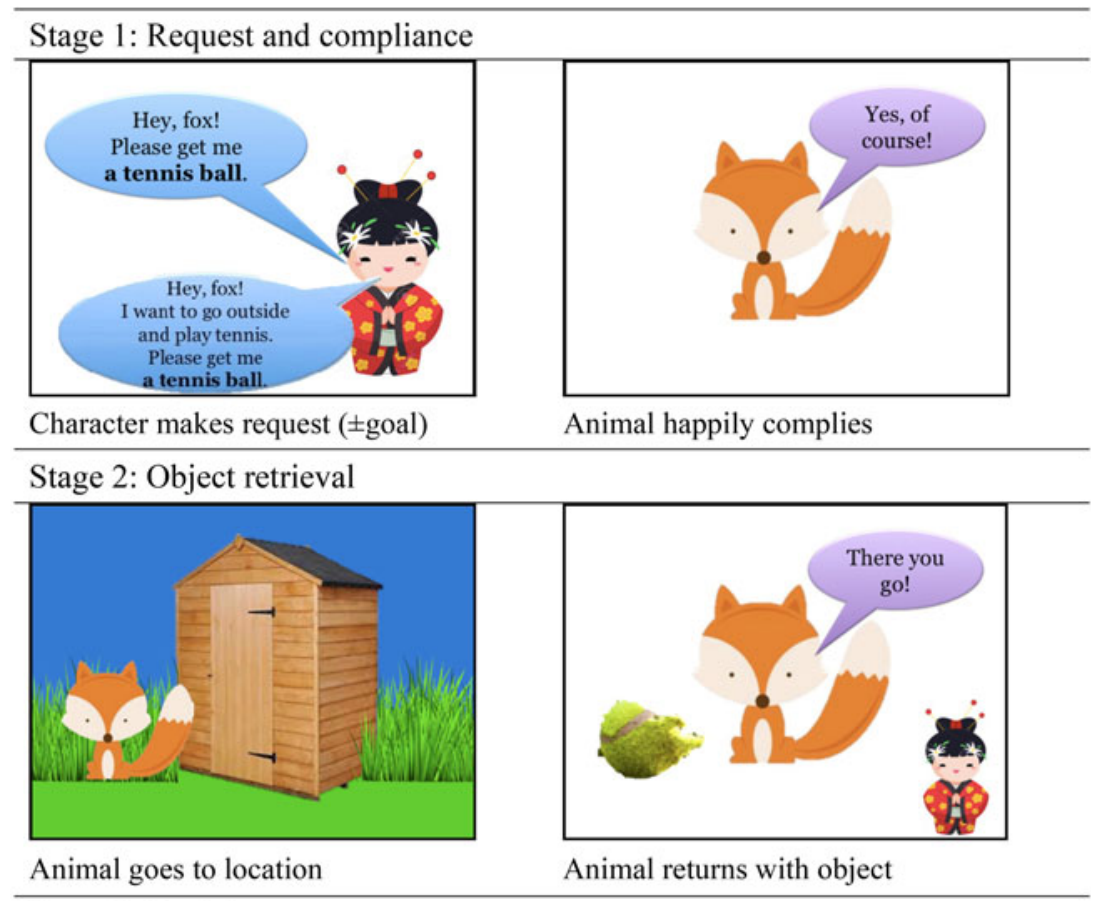

Stage 3: Participant assessment

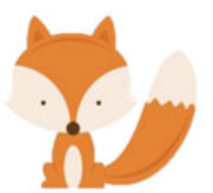

Did it well

Kind of did it

Didn't do it
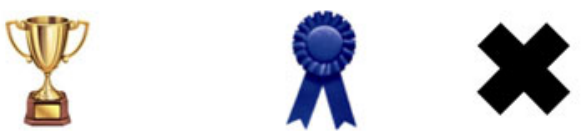

Figure 3. Sample target partial object test trial in Experiment 1

task (successfully implemented by Goro \& Akiba (2004), Katsos \& Bishop (2011), and Simon-Pearson \& Syrett (2018) for investigations of other linguistic phenomena).

The experiment session itself featured four test items and four control items, in a pseudorandomized order. The animal always returned with either a partial object (test items), a whole object of the kind specified by the count noun (control 1), or a whole object of a different kind than what was specified by the count noun (control 2). The experiment began with two training items, which did not feature a contrast between a partial object and a whole object of the same kind. During this time, participants were acclimated with how to assign the rewards. One group of participants heard a request modified by a speaker goal (+goal), while the other heard a request for an object without any additional information (-goal). 


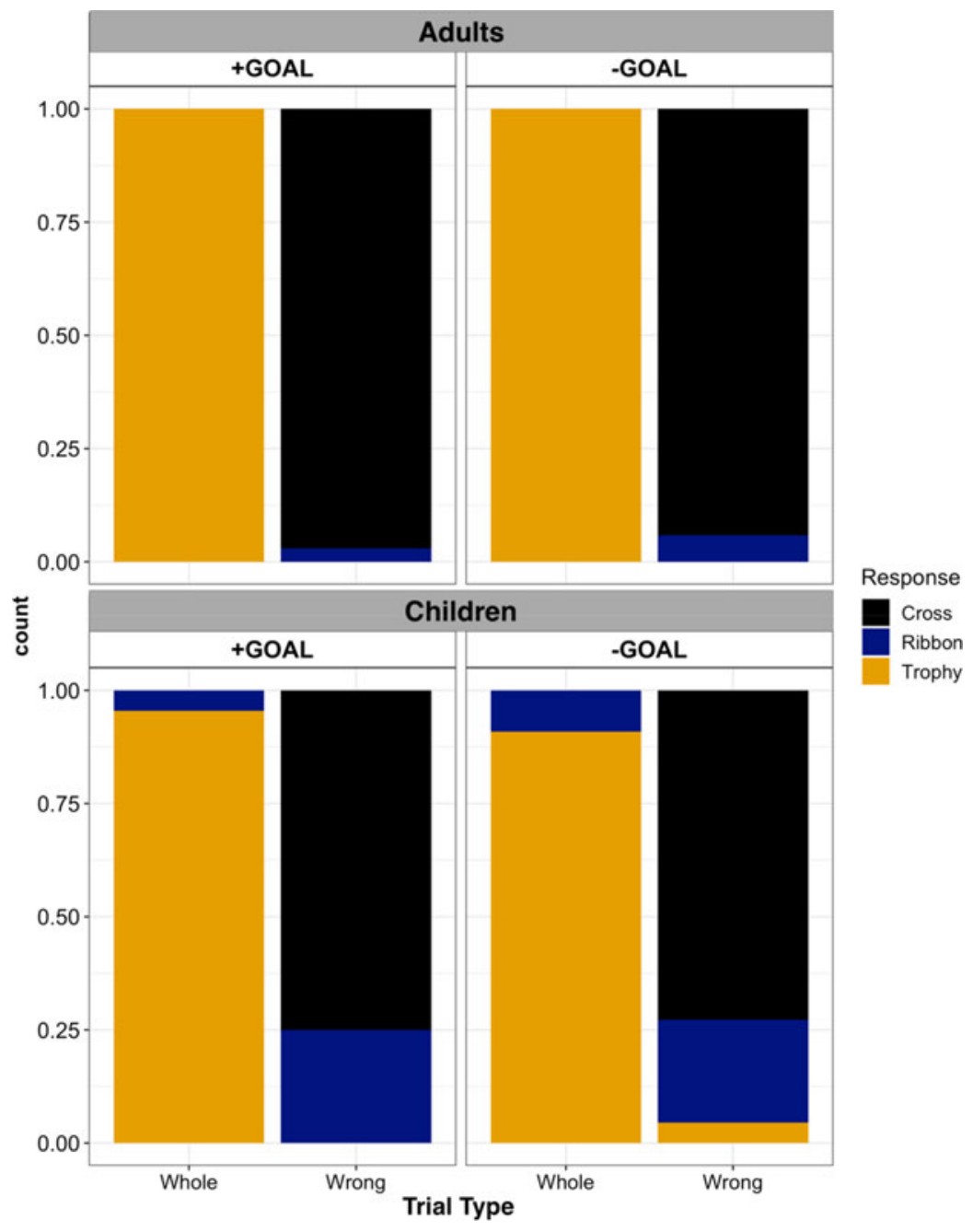

Figure 4. Performance on control trials in Experiment 1

\section{Results}

Adults behaved as anticipated on control and test items. Children were largely adult-like in the control trials, though their response patterns were less categorical than those of adults, especially on the wrong-object, wrong kind trials, to which we return momentarily. Both adults and children overwhelmingly awarded the trophy for 'whole-object, same kind' control trials (adults: 100\%; children: 93.2). When children did not award a trophy, they opted for the ribbon (6.8\%) and never chose the cross. In contrast, for the 'whole-object, wrong kind' control trials, the black cross was the dominant choice (adults: 95.6\%; children: 73.9\%). When children failed to offer the cross, they chose the ribbon $(23.9 \%)$. The trophy was rarely rewarded for a wrong kind $(2.3 \%)$. These patterns did not vary across goal specification for either group, as illustrated in Figure 4. 
The results for the test trials for the child and adult populations, split into the two \pm goal conditions, are presented in Figure 5. As is evident from the figure, adults consistently awarded the animal the blue ribbon and did not pattern differently between \pm goal conditions. While this is not immediately consistent with our expectations, we suspect this is because adults were able to infer the speaker's intent in the -goal condition, and so they filled in this information themselves. Children, on the other hand, were split between the three award types, though they were more likely to opt for the adult-like choice in the + goal condition.

We then conducted a second set of analyses on these partial object data to explore age and goal effects further. We divided children into two groups based on age, with children falling below the median age $(4 ; 7$ years) categorized as the "younger" group (3;3-4;6; 9 boys 11 girls), and those falling above the median as the "older" group (4;7-6;1; 14 boys 10 girls). Gender and age was relatively balanced for within these four groups: 'no goal' younger $(\mathrm{n}=10 ; 4$ boys 6 girls; $3 ; 3-4 ; 6)$, 'no goal' older $(\mathrm{n}=12$; 8 boys 4 girls; $4 ; 7-6 ; 2)$, 'goal' younger ( $\mathrm{n}=10 ; 5$ boys 5 girls; $3 ; 4-4 ; 6)$, 'goal' older $(\mathrm{n}=12 ; 6$ boys 6 girls; 4;7-5;7). Figure 6 represents children's reward assignments across age group (older/younger) and \pm goal condition.

We then fit a log-linear mixed-effects regression with observed frequencies/counts as the dependent measure and Response Type (Cross, Ribbon, Trophy), Condition ( \pm goal) and Age Group (older children, younger children) as fixed factors. Response Type was helmert-coded to test for the effects of i) Ribbon vs. Trophy and ii) Reward (Ribbon or Trophy) vs. No Reward (Cross). AgeGroup was dummy coded with younger children as the reference level. Condition was dummy coded with -Goal as the reference level. Results from the model are summarized in Table 1.

Children were overall more likely to give a cross (vs. a trophy or ribbon) in the +goal condition, suggesting some sensitivity to goal specification. Older children were also significantly more likely to give a blue ribbon (vs. a trophy) than the younger group, but this effect interacted significantly with goal: a positively specified goal decreased the rate of awarding the trophy for a partial object. There was no such interaction in the case of younger children, indicating that they were not sensitive to the effect of goal. ${ }^{2}$

\section{Discussion}

The main findings from Experiment 1 are two-fold. First, our results indicate that children did not uniformly treat partial objects as if they were on par with wholes. Children were sensitive to the distinctions between partial and whole objects: irrespective of context, neither the younger nor the older age groups consistently awarded the animal a trophy for returning with a partial object. On a story on which children simply do not perceive a difference between the partial and whole objects and their role as referents for the target count nouns, such discrimination is unexpected.

\footnotetext{
${ }^{2}$ After doing this post hoc split, we returned to the control trials to verify the children's performance on these trials within each group. In doing so, we found that older children were slightly more likely to assign a ribbon than a black cross for those trials where the animals returned an object of a different kind. This effect seems to have been driven by one trial, in which a frog was asked to retrieve a spoon, and returned a slatted spatula (which many children referred to as a 'pancake flipper'). We find this pattern intriguing, since we think that the older children may have thought that since both items are members of the same superordinate category 'kitchen utensils' the animal's actions were moderately accessible, and not deviant enough to merit a black cross. We think adults assigned a black cross, because of their familiarity with the labels for each object and their respective object functions.
} 


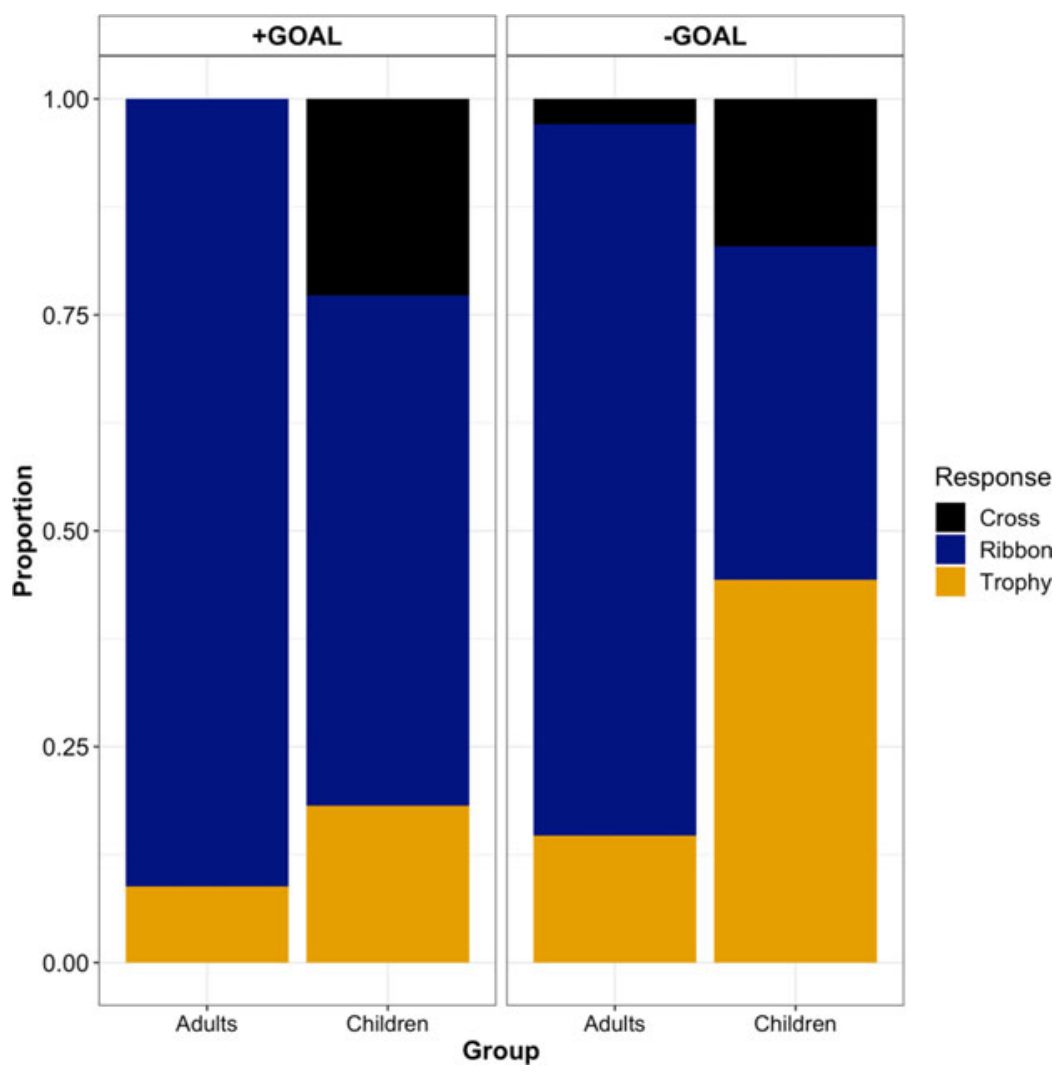

Figure 5. Performance on test trials in Experiment 1

Second, with older children, we find a strong effect of context: when the speaker's goals were explicitly stated, these children consistently adopted more stringent standards for the application of noun, awarding the target ribbon, rather than a trophy, to those helpers who returned with a partial object. Consistent with our semantic account, these older children were able to integrate contextual factors, like the speaker's goals, to assess whether or not a given count noun applies to an object IN THAT CONTEXT. In this respect, the two child age groups differed: whereas the older children overwhelmingly awarded a blue ribbon for partial objects when the speaker expressed an intention, the younger children's rates of choosing the ribbon over the trophy did not change. However, even with the younger group, there is some indication of sensitivity to context, even though it does not manifest in an adult-like manner: across age groups, children were altogether less likely to reward a helper who brought back a partial object, when the speaker's goal for an object was provided.

Interestingly, adults also did not differentiate between the two conditions, but in a different way, awarding the blue ribbon the vast majority of the time. However, we suggest that the null effect of condition observed in adults in this task is due to a design feature that distinguishes this task from those in Aravind and Syrett (2017) the presence of an agentive protagonist. Adults, being highly experienced conversationalists, may be ascribing to this character goals and intentions vis-à-vis 


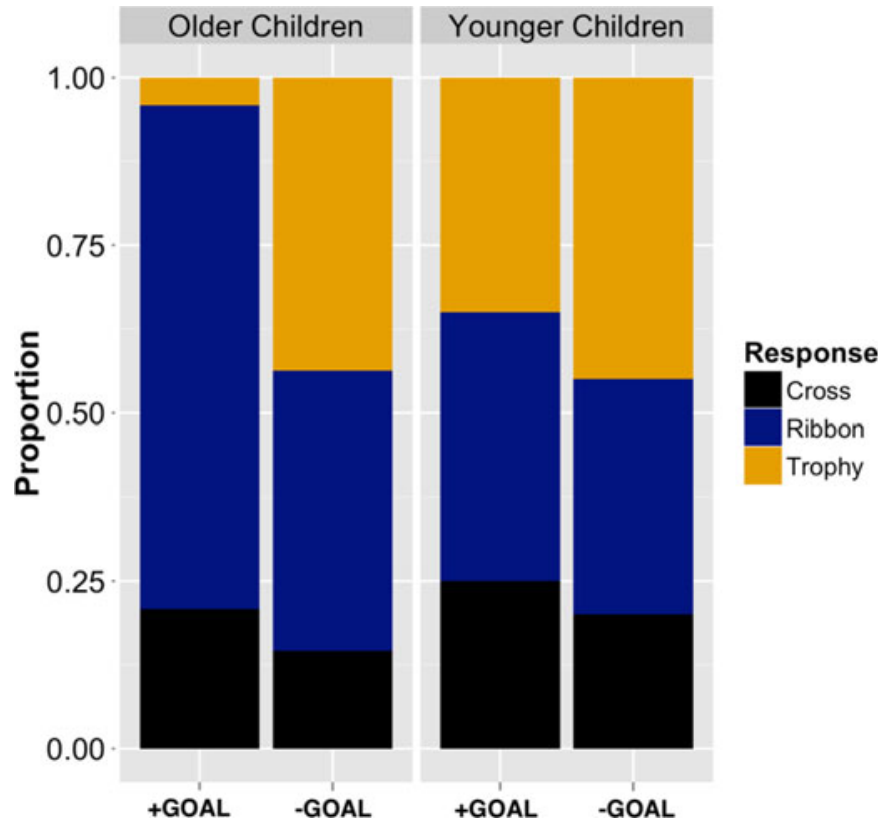

Figure 6. Performance by two groups of children on test trials in Experiment 1

Table 1. Analysis of experimental results split by age group

\begin{tabular}{lcccc}
\hline & Estimate & SE & $z$ & $p$-value \\
\hline Ribbon.v.Trophy: Goal & 1.47 & 0.40 & 3.717 & $<.001^{*}$ \\
\hline Reward.v.NoReward: Goal & 0.41 & 0.21 & 1.96 & $0.05^{*}$ \\
\hline Ribbon.v.Trophy: OlderKids & -0.10 & 0.24 & -0.427 & 0.67 \\
\hline Reward.v.NoReward:OlderKids & 0.13 & 0.19 & 0.683 & 0.49 \\
\hline Goal:OlderKids & 0.50 & 0.387 & 1.300 & 0.19 \\
\hline Ribbon.v.Trophy:Goal:OlderKids & -1.278 & 0.47 & -2.713 & $0.007^{*}$ \\
\hline Reward.v.NoReward:Goal:OlderKids & -0.319 & 0.277 & -1.152 & 0.25 \\
\hline
\end{tabular}

the requested object even when they are left implicit. Why else would a character request a tennis ball unless they were going to use it for its intended purpose? However, to probe adults further, we present the results of two additional tasks, showing that in the right contexts, adults DO pattern with children, allowing DPOs to serve as referents for count nouns.

\section{Experiment 2}

Here, we ask, in the absence of any contextual cues that might push count noun interpretations one way or other, and in the absence of any presupposition of 


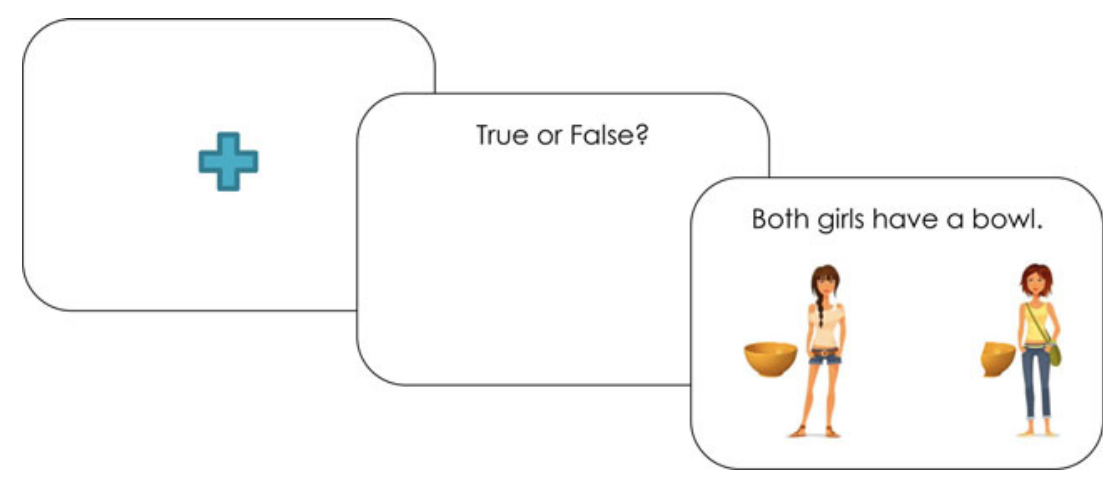

Figure 7. Trial structure for Experiment 1

existence accompanying a definite description which might force accommodation, are adults willing to treat a DPO as falling under the noun extension for the purpose of evaluating truth conditions?

\section{Participants}

32 adults participated. All were undergraduates in Linguistics or Cognitive Science courses who earned extra credit for their participation.

\section{Stimuli and Procedure}

Participants saw a series of 30 trials presented as PowerPoint slides, with the structure in Figure 7 and the lead-in and description combination in (1). The task was automated. Participants clicked through the instructions and slides on their own and indicated their responses on a paper response sheet. They were asked not to review or change their answers.

(1) Lead-in: True or False?

Description: Both \{girls/boys\} have an X.

The set of trials included 10 items featuring a partial target object and a whole target object, 10 with two whole target objects, five trials with whole targets alongside wholes of another kind, and five trials with two whole non-target objects. Target objects included mugs, bowls, forks, hats, balls, spatulas, cups, spoons, plates, shoes. Images were edited in PowerPoint using the 'remove background' to create the partial version of the object. Examples of image pairs for two sample prompts are featured in Figure 8.

If adults only allowed whole objects to serve as referents for a count noun, and excluded DPOs, (especially when a definite description did not prompt presupposition accommodation, as it may have in Aravind \& Syrett, 2017), they should only accept the target statement as true in the 'whole-whole' trials. If, on the other hand, they did allow for DPOs to satisfy the truth conditions of a sentence containing a count noun (in indefinite form), they should accept the statement some significant percentage of the time in the 'partial-whole' trials. Based on findings in Experiment 1, we do predict, however, that adults will find DPOs degraded referents for a count noun and, as such, 


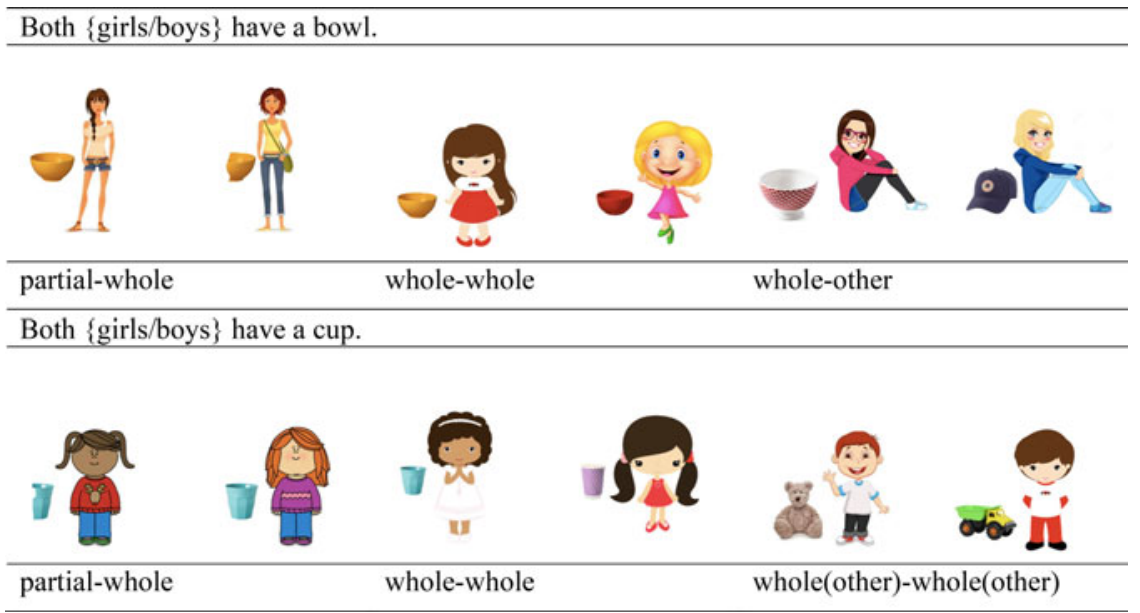

Figure 8. Example stimuli used in Experiment 2

that the percentage of acceptance for the 'partial-whole' trials will be suppressed relative to that of the 'whole-whole' trials.

\section{Results}

We begin with the control items. As expected, acceptance of the target statement was at floor when neither character had an object of that kind ('whole(other)-whole(other)', $0 \%)$, close to floor when only one of the two characters had an object of that kind ('whole-other', 5.7\%), and at ceiling when both characters had a whole object of that kind ('whole-whole', 100\%). For the 'partial-whole' trials, participants accepted the statement $65.7 \%$ of the time, which was above chance level (Wilcoxon signed rank test from chance $=.5, \mathrm{~V}=6486, p=0.0002$ ). This pattern was significantly lower than the overall acceptance in the 'whole-whole' trials (Wilcoxon signed rank comparison, $\mathrm{W}=-1176$, $\mathrm{z}=-6.03, p$ (two-tailed) $<.0001)$, indicating that participants detected a difference between the two trial types, and that the DPOs rendered the situation degraded. $72 \%$ of the participants allowed the statement to be true on $9 / 10$ or $10 / 10$ of the occasions.

When we looked further into the individual pattern of acceptance among participants for the 'partial-whole' and 'whole-whole' trials, we found a $65.7 \%$ rate of agreement, which is exactly the rate of acceptance in the 'partial-whole' trials. This pattern emerges from the fact that participants who chose to accept the statement in the 'partial-whole' trials always also accepted the 'whole-whole' trials, although acceptance of the 'whole-whole' trials did not guarantee acceptance of the 'partial-whole' trials (Phi coefficient of correlation $=-.46$, Pearson's Chi-squared test of association $\left.\chi^{2}=58.39, \mathrm{p}<.0001\right)$. Thus, a significant contingent of participants evaluated the statement similarly for partial-whole and whole-whole trials.

\section{Discussion}

Unlike in Experiment 1, adults in Experiment 2 allow DPOs to satisfy the truth conditions of the target statement. This finding lends preliminary support to the idea 
that adults' behavior in Experiment 2 was modulated by reasoning about the speaker's intent for the object, given its function, even in the absence of explicit goal statements. In the absence of any facilitative contextual cues, in this experiment, adults judged count nouns as truthfully applying to DPOs. One might, however, object that it is possible that something like the Principle of Charity (Quine, 1960) or the Cooperative Principle (Grice, 1975) guided adults' truth assessments, leading to a willingness to accommodate the statement and accept it in these contexts. To demonstrate unambiguously that count nouns have an underspecified semantics, and thus permit reference to DPOs, we turn to a task that does not involve judgments of truth, thereby allowing us to evaluate the robustness and generality of this inclusive behavior in support of our semantic account.

\section{Experiment 3}

In Experiment 3, we carried out a counting task inspired by those administered to child participants in previous developmental studies, while still manipulating contextual signaling of the speaker's goals. ${ }^{3}$

\section{Participants}

56 native speakers participated. As before, all participants were undergraduates who earned extra credit for their participation. Data from 8 additional participants were excluded for non-native status.

\section{Stimuli}

Visual stimuli were images of real objects (domestic artifacts) collected from the web. Critical objects included bowls, goggles, hairbrushes, hammers, mugs, scissors, shovels, spatulas, spoons, and sunglasses. Objects were assembled into three types of displays, as shown in Figure 9, manipulating whether the target partial objects appeared alongside whole artifacts of the same object kind, whole artifacts of a different object kind, or whole artifacts of same and different kinds. All participants saw all three types of displays. This manipulation allowed us to test for whether implicit contrast among comparison classes of object kinds exerted an influence. (Post-hoc analysis showed that it did not.) Target items appeared as distractors in control trials, and control objects appearing with target objects in the 'two object kind' target displays also appeared in control trials, either as distractors or targets in those trials, as in Figure 10. Each display had between four and seven objects total.

There were thirty critical trials, thirty control trials, and twenty fillers. Fillers featured clipart images not appearing in the target or control trials, and were included to ensure attentiveness (Figure 7). All participants saw the same control and filler stimuli.

\footnotetext{
${ }^{3}$ Here we include a caveat: the previous developmental counting studies with DPOs featured unnaturally split whole objects whose parts were merely separated by a space (or gave the impression of a small occlusion between the DPOs), permitting a 'fusion' of the DPOs to reconstruct the whole. In such cases, adults either disregarded the DPOs or else 'fused' together to count as a whole object (see Shipley \& Shepperson, 1990). Indeed, in a separate version of Experiment 3 in which we presented participants with stimuli in which there was such a clean sever among DPOs, this was the pattern we observed. We therefore extend this counting task to DPOs that instantiate a more natural split-one that is consistent with the stimuli featured in the two previous tasks. Thus, in Experiment 3 we ask if, when given DPOs as one might encounter in the real world, adults would include them in their count.
} 


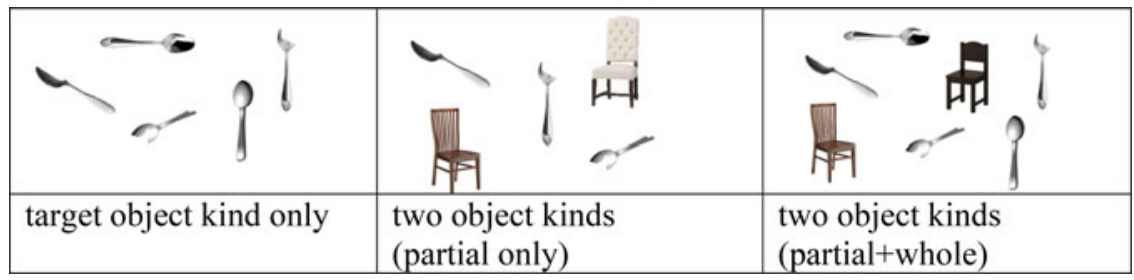

Figure 9. Example target stimuli and Comparison Classes for trial ( $\mathrm{am}$ going to eat some soup.) Count the spoons (I can use.)

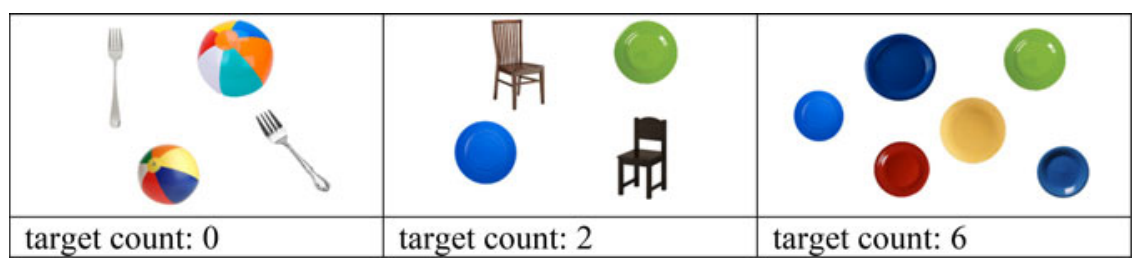

Figure 10. Example control stimuli for trial (I am going to eat dinner.) Count the plates (I can use.) Target objects also appeared as distractors in other control stimuli (e.g., I am going to play tennis. Count the tennis balls I can use.)

\section{Procedure}

In each trial, the first screen displayed the objects, as shown above, with printed instructions above them. There were two between-subject versions of the instructions, as in (2): one with a simple prompt to count the objects (a), and another (b) where the prompt included a statement of the speaker's goal and a reduced restrictive clause modifying the count noun ( $I$ can use). Thus, in the second version, the linguistic context provided further criteria for inclusion/exclusion of objects as units of Ns. Participants were randomly assigned to one of these two conditions.

(2) a. No context (simple instructions): Count the spoons.

b. Context: I am going to eat some soup. Count the spoons I can use.

The second screen included a question How many did you count? above a series of numbers ordered from 0 to 7 . Displays were designed so as to allow us to predict a target count between 0 and 5 (thus within or just beyond the subitizable range, so that the counting task did not place a cognitive load on the participants).

\section{Results}

Participants' counts in target trials were coded for whether they included AT LEAST ONE PARTIAL OBJECT or ONLY WHOlE OBjeCts. Plots and inferential statistics (e.g., model estimates, CIs) were fit to proportion of partial-object-inclusion. See Figure 12 for percentage of partial object inclusion.

A hypothesis-driven mixed-effects model compared INCLUSION OF PARTIAL OBJECTS in the count across condition (context vs. no context) and object comparison class 


\begin{tabular}{|l|l|l|}
\hline target: purple diamonds & target: question marks & target: yellow squares \\
\hline target count: 0 & target count: 3 & target count: 5 \\
\hline
\end{tabular}

Figure 11. Example filler stimuli

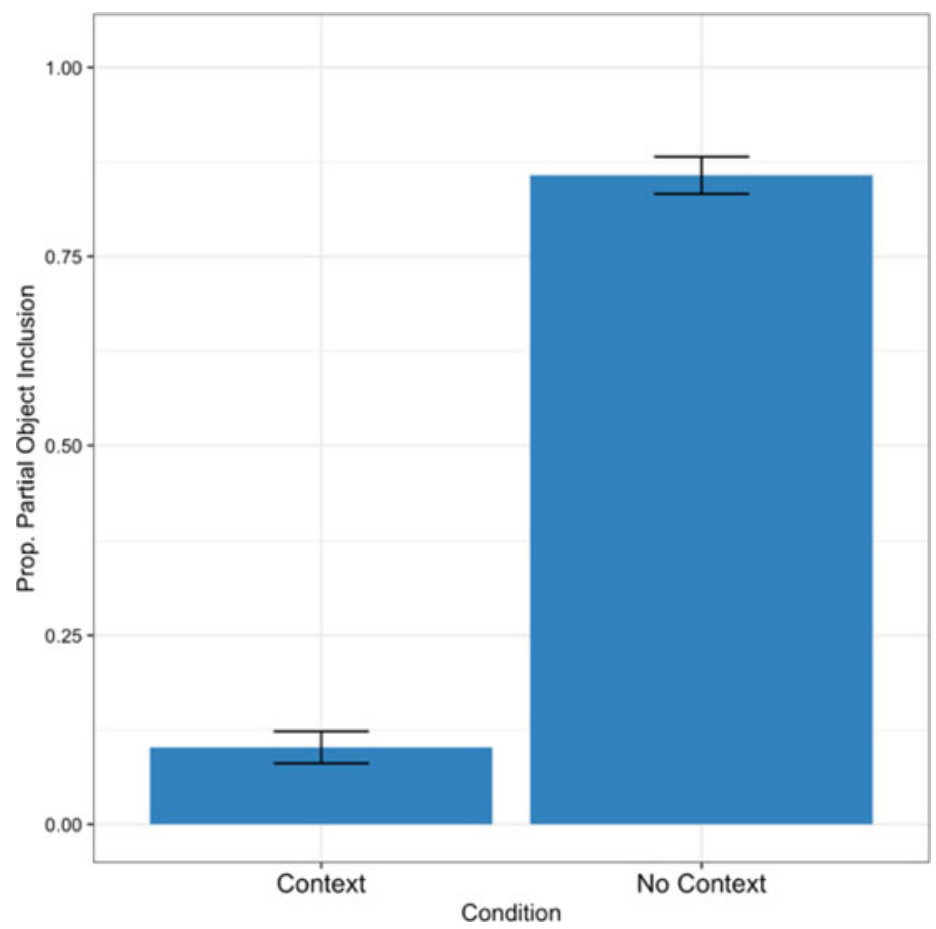

Figure 12. \% INCLUSION of partial objects in counting as a function of Context

(target object kind only, two object kinds (partial only), two object kinds (partial + whole)). The model revealed a Main Effect of Context: participants' inclusion of partial objects was higher in the No-Context condition relative to the Context condition (Model syntax: IncludePartial Context * Comparisonclass + (ComparisonClass|Participant) $+(1 \mid$ Item $) ; \beta=10.37, \mathrm{SE}=1.8524, \mathrm{z}=$ $5.596, \mathrm{p}<.001)$. There was no Main Effect or Interaction of the Comparison Class contrast. We leveraged likelihood ratio tests to evaluate model fit by assessing whether the inclusion of the key predictor significantly reduced residual variance. 
Doing so revealed that a model including Context as a predictor was significantly better than one without $\left(\chi^{2}=55.186, \mathrm{p}<.001\right)$.

\section{Discussion}

The findings of Experiment 3 complement and extend those from Experiment 2: adults willingly include DPOs in their count when asked to count the instances of objects referred to by a count noun. It did not matter if there were objects of another comparison class present or not. Quite strikingly, adults did not require additional contextual support to include partial objects. In fact, what we observed was that participants used contextual information to RESTRICT reference and become more conservative about what counted as objects of that kind. When participants were told that the speaker's intention was to e.g., use the spoons to eat soup, they excluded partial spoons from the count.

If children's willingness to count DPOs as wholes were a sign of a delay in the crystallization of their conceptual or linguistic representations, we would have no way of explaining why adults - who surely possess this range of knowledge - display a similar proclivity to count partials, albeit in a context-sensitive manner. Adults' behavior can, however, easily be explained if we assume that count nouns are intrinsically semantically underspecified with respect to what counts as 'one' and rely on the context by default to determine units for counting, consistent with the view we have put forth in this paper.

\section{General discussion}

We began this paper by remarking on the fact that although children understand and produce count nouns early in language development, they do not appear to appreciate the restrictions on the nature of the objects they denote, routinely allowing partial objects to serve as referents for the purpose of counting and comparison of quantities. The stance we have taken in this paper, though, is that this very behavior, while diverging from that of adults, is perhaps counterintuitively indicative of the fact that children actually appreciate something central to the semantic representations of count nouns: that count nouns depend on the context for determining what counts as an atomic individual, and may in fact allow for partial objects to fall under their extension. Consequently, we find that not only children, but also adults, take a partial object to serve as a viable candidate referent for a count noun, depending on aspects of the context.

One of the main contributions of the present work is to offer support for the semantic hypothesis from children, and illustrate that, depending on aspects of the context at hand, children restrict their application of a count noun to whole objects alone and do not allow partial objects to serve this role. Perhaps it is true that in everyday conversation when we use a count noun to talk about artifacts such as forks or balls, what we typically have in mind is a whole object (perhaps indeed because we are aware of the intended use and how the object will fulfill this function). But this does not preclude the count noun fork applying to partial forks, unusable forks, etc., in some other context, where the standards differ. Thus, whole objects are not the ONLY potential referent; they are privileged nominal referents, and adults have acquired this knowledge in their experience in the world over time. Our experimental results provide preliminary evidence that children are sensitive to this 
distinction between partial and whole objects in a given context; whereas they almost always assigned the highest reward to whole objects of the right kind, their behavior was more variable with partial objects. We would predict a more categorical response to develop over time.

Secondly, our findings shed light on where the child-adult difference lies. We propose that the difference is not in children working with a different set of conceptual representations of the relevant sortals. We also propose that it does not boil down to them having difficulty accessing more optimal alternatives. Rather, children are less adept than adults at picking up on contextual cues to restrict the noun's application accordingly. Adults readily integrate context-specific information (e.g., the speaker's goals and intent) in making decisions about what constitutes a suitable referent for the count noun. Older children can also tailor their behavior in accordance with such contextual cues, but only when the cues are explicit. For younger children, making use of contextual cues to tighten or loosen the domain of application of the noun is not automatic, even when those cues are explicit. In sum, our findings show that the developmental shifts lie in becoming attuned to aspects of the context that affect count noun interpretation, either restricting the noun's reference to whole objects only or permitting reference to a broader membership of entities exhibiting some degree of the property denoted by that noun.

We have suggested, thus, that young children's behavior goes awry in allowing too much 'slack' in what they allow to be counted as an atomic individual. Indeed, this might reflect a more systematic pattern of performance linked to the identification of atomic individuals falling under the extension of a count noun. Below, we show that this idea can offer a fresh perspective and new insights on independent findings from the literature that at first blush might appear to be unrelated. We offer three such cases, involving telicity, distributivity, and maximality, respectively.

The first concerns experimental findings on children's understanding of event culmination and the language used to describe it cross-linguistically. Just as the objects denoted by count nouns give rise to a natural mode of individuation, some events are TELIC, and have an inherent endpoint (Vendler, 1957; Bach, 1986). Telicity may be encoded in different ways within and across languages. For example, it may be a feature of the lexical semantics of a verb, as shown in (1). The predicates in (a) are telic, while those in (b) are not.
(1) a. Anna \{graduated / opened the present\}.
b. Anna \{laughed / moved the furniture\}.

Telicity may also be encoded compositionally via the presence of a nominal direct object argument, as in (2), or via perfective morphology or a verb particle, as in (3).

(2) a. Anna \{ate v. ate a sandwich\}.

b. Anna \{painted v. painted a landscape $\}$.

(3) a. Anna $\{$ drew v. is drawing $\}$ a circle.

b. Anna \{ate ice cream v. ate up the ice cream\}.

As some of these examples illustrate, the presence of a nominal argument alone does not automatically signal event culmination. Nor does a count noun alone signal telicity. However, it serves as a very strong cue, as in (2). Thus, (4a) seems to signal 
a telic event, while (4b) does not. (One way to test this difference is to stop the event mid-stream and ask if the sentence is true.)

(4) a. Anna ate a sandwich.

b. Anna ate ice cream.

The acquisition of telicity has long posed a puzzle to developmentalists. On the one hand, evidence from spontaneous production and judgment tasks suggests that young English-learners are sensitive to lexically- and morphologically-encoded cues to telicity (Bloom, Lifter \& Hafitz, 1980; Shirai \& Anderson, 1995; van Hout, 1998, 2000; Schulz \& Penner, 2002; Wittek, 2002), and differentiate between telic and atelic events and the language used to describe them (Wagner \& Carey, 2003; Wagner, 2006). At the same time, in tasks employing methodologies such as Truth-Value Judgment or Picture-Sentence Matching, children as old as five seem to have trouble understanding how direct objects influence the telicity of the predicate (van Hout, 1998, 2000; Schulz \& Penner, 2002; Ogiela, 2007). For example, van Hout (2000) showed children events where one mouse ate a whole wheel of cheese, but another one ate only a half a wheel, and then asked for each mouse whether the mouse "ate" or "ate up" his cheese. The latter could only be true of the first mouse; however, children consistently allowed this telic expression to be predicated of the second mouse.

Our findings offer a novel perspective on this pattern of results and a reconciliation of the conflicting findings. Rather than place the blame squarely in children's lack of sensitivity to certain aspects of telicity, we might appeal to children's flexibility in count noun to object mapping, and their willingness to allow partial objects to serve as a referent for a singular count noun. The result is that they end up over-accepting telic predicates in cases of 'partial completion' contexts. This hypothesis seems to have been borne out in the studies of Wagner and Carey (2003), who reported that despite their ability to discriminate between telic and atelic predicates, when given a telic description, children were more likely than adults to rely on spatio-temporal criteria of individuation. Indeed, our story may be consistent with Schulz's (2018) proposal that, in spite of the apparently conflicting findings, children do follow an 'endstate orientation'.

A second case study comes from work on collective and distributive interpretations of sentences with pluralities, such as the ones in (5).

(5) a. Two girls (each) built a tower.

b. Two girls (each) completed a puzzle.

Without the overt distributivity marker and universal quantifier each, these sentences permit two interpretations: a collective interpretation in which the two girls work together to perform the event expressed by the predicate (e.g., build a tower, complete a puzzle) and neither girl performs the action on her own, and a distributive interpretation in which the event can be predicated of each individual girl. Syrett and Musolino (2013) presented short videos of individuals performing such actions to children and adults, each video favoring either the collective or distributive interpretation. The presence or absence of each was manipulated between subjects. While the versions of the sentences without each should be ambiguous, the insertion of each should rule out the collective interpretation and force the distributive one. 
Both children and adults accessed the two interpretations of the ambiguous version, but only adults restricted the interpretations to the distributive one in the presence of each. In light of other developmental findings on children's performance with each (versus all or every), and a theoretical account of distributivity offered by Champollion (2015), Syrett (2015) proposed that one place where children could diverge from adults is in their inability to appreciate the way in which each forced distribution over atomic individuals, and how these atomic individuals are determined. Thus, much like with partial objects, children allow sentences such as those in (5) modified by each to be true, just in case each girl has the property of building a partial tower or completing a partial puzzle, because she was a participant in an event of this kind.

Finally, the third example comes from investigations of the maximality component of plural definite descriptions, such as the strawberries or the cars. Across tasks, children have been shown to not recognize that a plural definite description picks out all of the elements in the relevant set (Caponigro, Pearl, Brooks \& Barner, 2012; Karmiloff-Smith, 1979; Simon-Pearson \& Syrett, 2018; Tieu, Križ \& Chemla, 2019). This definite linguistic expression should in principle have this function, since the atomic individuals are closed under the sum operation to become a MAXIMAL ELEMENT (Link, 1983). The plural definite description should pick out this maximal element. However, Moyer, Husnain, and Syrett (2019) point out that definite descriptions do not ALWAYS require reference to the maximal element; for example, they can pick out a kind, be used imprecisely, and, most importantly for our purposes here, evoke implicit domain restriction such as that one can narrow reference to a relevant (salient, familiar) subset (in a similar way as with universal quantification) (von Fintel, 1994; Geurts \& van der Sandt, 1999). Moyer, Husnain, and Syrett demonstrate that at four years of age, children and adults alike do precisely this. If in fact children interpret count nouns as licensing reference to partial objects, then non-maximal instances of definite description interpretation might indeed be an instance of this process.

What each of these cases might have in common is children's willingness to allow an element smaller than the whole object to fall under the extension of the relevant linguistic expression, thereby reflecting their difficulty in identifying what serves as the atomic individual in the relevant context. That they do this across the board, but at the same time show limits and sensitivity to elements of the context, seems to indicate two things. First, this behavior is not tied to a particular expression or the availability of alternative expressions, and second, the linguistic interpretation interacts with (or more strongly, depends on) how it is presented and situated in the larger discourse context.

To summarize, we have argued that children's counting of DPOs observed in previous developmental work arises from the context-dependence inherent to the semantic representation of count nouns: what counts as 'one' is at least in part determined by the context. We have further argued, based on independent evidence from adults and our current non-counting referential task, that children's seemingly non-adult counting behavior does not signal a radical discontinuity from adult representations. In some ways it is not surprising to see children diverge from adults despite this common ground: figuring out the relevant contextual features that determine the level of granularity for what counts as an atomic individual in a domain requires a fair amount of world knowledge and sophisticated mentalizing abilities. In placing the burden of explanation where we do, we are led to new theoretical and empirical questions. What are the contextual factors that we as 
speakers consider when identifying the threshold for whether or not some entity counts as one atomic individual and falls under the extension of the count noun? What aspects of the context that adults recruit do children also recruit (or not) and what do these have in common? How would children fare in the same tasks adults have participated in, where they are asked to rapidly locate an object referent or assign a truth value faced with a display containing partial and whole objects? We find these to be fascinating questions for future research in which we are actively engaged.

Acknowledgements. We are grateful to the Associate Editor, two anonymous reviewers, the audiences at LSA 2017, NELS 2017, BUCLD 2017, the University of Hawai'i-Manoa, UC Santa Cruz, Boston University, University of Massachusetts - Boston, CUNY Graduate Center, Heinrich Heine University, and UC Berkeley for their constructive and insightful comments. We are especially grateful to our students and members of our labs, who helped to bring these experiments to fruition every step of the way.

\section{References}

Aravind, A., \& Syrett, K. (2017). Investigating context sensitivity and vagueness in nominals in child and adult language. Poster presented at the North East Linguistics Society (NELS). University of Iceland, Reykjavik, Iceland, October 27-29.

Bach, E. (1986). The algebra of events. Linguistics and Philosophy, 9, 5-16.

Balaban, M. T., \& Waxman, S. R. (1997). Do words facilitate object categorization in 9-month-old infants? Journal of Experimental Child Psychology, 64, 3-26.

Bergelson, E., \& Swingley, D. (2015). Early word comprehension in infants: Replication and extension. Language Learning and Development, 11, 369-380.

Bloom, P. (1994). Semantic competence as an explanation for some transitions in language development ( pp 41-76). In Y. Levy (Ed.), Other children, other languages: Theoretical issues in language development. Hillsdale, NJ: Erlbaum.

Bloom, P., \& Kelemen, D. (1995). Syntactic cues in the acquisition of collective nouns. Cognition, 56, 1-30.

Bloom, L., Lifter, K., \& Hafitz, J. (1980). Semantics of verbs and the development of verb inflection in child language. Language, 56, 386-412.

Brooks, N., Pogue, A., \& Barner, D. (2011). Piecing together numerical language: Children's use of default units in early counting and quantification. Developmental science, 14, 44-57.

Caponigro, I., Pearl, L., Brooks, N., \& Barner, D. (2012). Acquiring the meaning of free relative clauses and plural definite descriptions. Journal of Semantics, 29, 261-293.

Champollion, L. (2015). The interaction of composition semantics and event semantics. Linguistics and Philosophy, 38, 31-66.

Chierchia, G. (2010). Mass nouns, vagueness, and semantic variation. Synthèse, 174, 99-149.

Dewar, K. M., \& Xu, F. (2007). Do 9-month-old infants expect distinct words to refer to kinds? Developmental Psychology, 43, 1227-1238.

Dewar, K. M., \& Xu, F. (2009). Do early nouns refer to kinds or distinct shapes? Evidence from 10-month-old infants. Psychological Science, 20, 252-257.

Fenson, L., Dale, P. S., Reznick, J. S., Bates, E., Thal, D. J., Pethick, S. J., Tomasello, M., Mervis, C. B., \& Stiles, J. (1994). Variability in early communicative development. Monographs of the society for research in child development, i-185.

Foppolo, F., Guasti, M. T., \& Chierchia, G. (2012). Scalar implicatures in child language: Give children a chance. Language Learning and Development, 8, 365-394.

Gelman, R., \& Gallistel, C. R. (1976). The child's understanding of number. Cambridge, MA: Harvard University Press.

Geurts, B., \& van der Sandt, R. (1999). Domain restriction. In Peter Bosch, Rob van der Sandt (Eds.), Focus: linguistic, cognitive, and computational perspectives (pp. 268-292). Cambridge University Press, Cambridge,

Gordon, P. (1985). Evaluating the semantic categories hypothesis: The case of the count/mass distinction. Cognition, 20, 209-242. 
Goro, T., \& Akiba, S. (2004). The acquisition of disjunction and positive polarity in Japanese. In Proceedings of the 23rd West Coast conference on formal linguistics (WCCFL) (pp. 251-264). Summerville, MA: Cascadilla Press.

Grice, H. P. (1975). Logic and conversation. In P. Cole, and J. Morgan (Eds.), Syntax \& Semantics, 3.

Guasti, M. T., Chierchia, G., Crain, S., Foppolo, F., Gualmini, A., \& Meroni, L. (2005). Why children and adults sometimes (but not always) compute implicatures. Language and Cognitive Processes, 20, 667-696.

Kamp, H., \& Partee, B. (1995). Prototype theory and compositionality. Cognition, 57, 129-191.

Karmiloff-Smith, A. (1979). A functional approach to child language: A study of determiners and reference. Cambridge: Cambridge University Press.

Katsos, N., \& Bishop, D. (2011). Pragmatic tolerance: Implications for the acquisition of informativeness and implicature. Cognition, 120, 67-81.

Kennedy, C. (2007). Vagueness and grammar: The semantics of relative and absolute gradable adjectives. Linguistics \& Philosophy, 30, 1-45.

Krifka, M. (1989). Nominal reference, temporal constitution and quantification in event semantics. In R. Bartsch, J. van Bentham, and P. van Emde Boas (Eds.), Semantics and Contextual Expressions (pp. 75-155). Dordrecht: Foris.

Landman, F. (2011). Count nouns-mass nouns, neat nouns-mess nouns. Baltic International Yearbook of Cognition, Logic and Communication, 6, 1-67.

Link, G. (1983). The logical analysis of plural and mass terms: A lattice theoretic approach. In R. Bäuerle, C. Schwarze \& A. von Stechow (Eds.), Meaning, use and interpretation of language (pp. 302-323). Berlin: de Gruyter.

Melgoza, V., Pogue, A., \& Barner, D. (2008). A broken fork in the hand is worth two in the grammar: A spatio-temporal bias in children's interpretation of quantifiers and plural nouns. In Proceedings of the 30th Annual conference of the Cognitive Science Society (pp. 1581-1585).

Moyer, M., Husnain, Z., \& Syrett, K. (2019). Won't somebody think of the children? Beyond maximality with plural definite descriptions. Proceedings of the $43^{\text {rd }}$ Annual Boston University Conference on Language Development (pp. 441-453). Somerville, MA: Cascadilla Press.

Ogiela, D. (2007). Development of telicity interpretation: Sensitivity to verb-type and determiner-type. Doctoral dissertation, Michigan State University.

Quine, W. V. O. (1960). Word and object. Cambridge, MA: MIT Press.

Rothstein, S. (2010). Counting and the mass-count distinction. Journal of Semantics, 27, 343-397.

Russell, B. (1905). On denoting. Mind, 14, 479-493.

Schulz, P. (2018). Telicity in typical and impaired acquisition. In K. Syrett \& S. Arunachalam (Eds.), Semantics in Language Acquisition, Trends in Language Acquisition (TiLAR) Series (pp. 123-150). Amsterdam: John Benjamins

Schulz, P., \& Penner, Z. (2002). How you can eat the apple and have it too: Evidence from the acquisition of telicity in German. In J. Costa, \& M.J. Freitas (Eds.), Proceedings of the GALA' 2001 Conference on Language Acquisition (pp. 239-246). Lisboa: Associação Portuguesa de Linguística.

Shipley, E. F., \& Shepperson, B. (1990). Countable entities: Developmental changes. Cognition, 34, 109-136.

Shirai, Y., \& Anderson, R. W. (1995). The acquisition of tense-aspect morphology: A prototype account. Language, 71, 743-762.

Simon-Pearson, L., \& Syrett, K. (2018). Assessing truth and speaker knowledge when utterances are not maximally true. In Anne B. Bertolini and Maxwell J. Kaplan (Eds.), Proceedings of the $42^{\text {nd }}$ Annual Boston University Conference on Language Development (pp. 708-721). Somerville, MA: Cascadilla Press.

Skordos, D., \& Papafragou, A. (2016). Children's derivation of scalar implicatures: Alternatives and relevance. Cognition, 153, 6-18.

Soja, N. (1992). Inferences about the meaning of nouns: The relationship between perception and syntax. Cognitive Development, 7, 29-45.

Srinivasan, M., Chestnut, E., Li, P., \& Barner, D. (2013). Sortal concepts and pragmatic inference in children's early quantification of objects. Cognitive Psychology, 66, 302-326.

Strawson, P. (1974). On referring. Mind, 59, 320-344. 
Sutton, P. R., \& Filip, H. (2016). Counting in context: Count/mass variation and restrictions on coercion in collective artifact nouns. In Mary Moroney, Carol-Rose Little, Jacob Collard, and Dan Burgdorf (Eds.), Proceedings of SALT 26 (pp. 350-370). Ithaca, NY: CLC Publications.

Syrett, K. (2015). Events and agents in the acquisition of universal quantification. Theoretical Linguistics, $41,211-222$.

Syrett, K., Austin, J., \& Sánchez, L. (2021). Establishing upper bounds in English monolingual and Spanish-English bilingual language development. Language Acquisition: A Journal of Developmental Linguistics, 1, 39-64.

Syrett, K., Kennedy, C., \& Lidz, J. (2010). Meaning and context in children's understanding of gradable adjectives. Journal of Semantics, 27, 1-35.

Syrett, K., \& Musolino, J. (2013). Collectivity, distributivity, and the interpretation of numerical expressions in child and adult language. Language Acquisition: A Journal of Developmental Linguistics, 20, 259-291.

Tieu, L., Križ, M., \& Chemla, E. (2019). Children's acquisition of homogeneity in plural definite descriptions. Frontiers in Psychology, 10, 2329. http://doi.org/10.3389/fpsyg.2019.02329

van Hout, A. (1998). On the role of direct objects and particles in learning telicity in Dutch and English. In A. Greenhill, M. Hughes, H., Littlefield, (Eds.), Proceedings of the $22^{\text {nd }}$ Annual Boston University Conference on Language Development (397-408). Somerville: Cascadilla Press.

van Hout, A. (2000). Event semantics in the lexicon-syntax interface: Verb frame alternations in Dutch and their acquisition. In C.L. Tenny \& J. Pustejovsky (Eds.), Events as grammatical objects. The converging perspectives of lexical semantics and syntax (pp. 239-282). Stanford: CSLI publications.

Vendler, Z. (1957). Verbs and times. The Philosophical Review, 66, 143-160.

von Fintel, K. (1994). Restrictions on quantifier domains. Doctoral Dissertation, University of Massachusetts, Amherst.

Wagner, L. (2006). Aspectual bootstrapping in language acquisition: Telicity and transitivity. Language Learning and Development, 2, 51-76.

Wagner, L., \& Carey, S. (2003). Individuation of objects and events: A developmental study. Cognition, 90, $163-191$.

Waxman, S. R., \& Braun, I. (2005). Consistent (but not variable) names as invitations to form object categories: New evidence from 12-month-old infants. Cognition, 95, B59-B68.

Waxman, S. R., \& Markow, D. (1995). Words as invitations to form categories: Evidence from 12- to 13-month-olds. Cognitive Psychology, 29, 257-302.

Wittek, A. (2002). Learning the meaning of change of state verbs: A case study of German child language. Berlin: De Gruyter Mouton.

Xu, F., Cote, M., \& Baker, A. (2005). Labeling guides object individuation in 12-month-old infants. Psychological Science, 16, 372-377.

Xu, F. (2002). The role of language in acquiring object kind concepts in infancy. Cognition, 85, 223-250.

Xu, F. (2007). Sortal concepts, object individuation, and language. TRENDS in Cognitive Sciences, 11, 400-406.

\section{Appendix: Experimental Stimuli}

\section{Item type: Target partial object, correct object kind}

Request [goal]:

Object animal retrieves:

Request [goal]:

Object animal retrieves:

Request [goal]:

Object animal retrieves:

Request [goal]:

Object animal retrieves:
[I'm thirsty. I want to drink some water.] Please get me a cup. partial cup

[I'm hungry. I want to eat some noodles.] Please get me a fork. partial fork

[I want to go outside and play tennis.] Please get me a tennis ball. partial tennis ball

[I think my hair is all messy and I want to fix it.] Please get me a comb. partial comb 


\section{Item type: Control whole object, correct object kind}

Request [goal]:

Object retrieved:

Request [goal]:

Object retrieved:
[I want to go outside and play baseball.] Please get me a baseball. in-tact baseball

[It's too sunny and hot outside.] Please get me a hat.

in-tact hat

\section{Item type: Control whole object, incorrect object kind}

Request [goal]:

Object animal retrieves:

Request [goal]:

Object animal retrieves:
[I'm hungry, I want to eat some soup.] Please get me a spoon. slotted pancake spatula

[I need to go outside, but it's raining.] Please get me an umbrella. hand-held American flag

Cite this article: Syrett K, Aravind A (2022). Context sensitivity and the semantics of count nouns in the evaluation of partial objects by children and adults. Journal of Child Language 49, 239-265. https://doi.org/ $10.1017 /$ S0305000921000027 